\title{
Interaction Analysis of Glycyrrhizin on Licorice Extract-Induced Apoptosis of Human Leukemia Cells by Knockout Extract
}

Takuhiro Uto, Nguyen Huu Tung, Osamu Morinaga and Yukihiro Shoyama*

Department of Pharmacognosy, Faculty of Pharmaceutical Sciences, Nagasaki International University, 2825-7 Huis Ten Bosch, Sasebo, Nagasaki 859-3298, Japan

\begin{abstract}
Licorice (Glycyrrhiza spp.) is the most frequently prescribed herb in traditional Chinese medicine (TCM) and Japanese Kampo medicine. Although glycyrrhizin (GC) is one of the major active components of licorice, the other components are also known to possess biological activities. We had previously prepared GC-knockout (GC-KO) extract, which contained all components of licorice extract (LE) except GC using an immunoaffinity column conjugated with anti-GC monoclonal antibodies (MAb). In this study, we used the GC-KO extract to investigate the potential role of GC in LE-induced apoptotic cell death. LE markedly induced apoptotic cell death in human leukemia HL60 cells. Although treatment with GC alone had no influence on cell viability, induction of cell death by the GC-KO extract was weaker than that by LE. Interestingly, the addition of GC to the GC-KO extract significantly rescued cell growth inhibition and activated caspase-3. These data suggest that GC may synergistically enhance the induction of apoptosis in the presence of other components of LE. Moreover, these pharmacological analyses indicate the utility of $\mathrm{KO}$ extracts in determining new functions of target compounds and the interactions between target compounds and other constituents of medicinal plant extracts.
\end{abstract}

Keywords: Licorice; Glycyrrhizin; Knockout extract; Immunoaffinity column; Apoptosis; HL-60

\section{Introduction}

Licorice (Glycyrrhiza spp.) is one of the oldest and most frequently prescribed herb in traditional Chinese medicine (TCM) and Japanese Kampo medicine [1,2]. In Western countries, licorice has been widely used as a flavoring and sweetening agent in foods, beverages, candies, tobacco, and dietary supplements. Licorice has various pharmaceutical activities including anti-inflammatory, anti-ulcer, anti-cancer, antivirus, anti-allergy, and hepatoprotective activities [3-5]. Numerous phytochemical investigations reported that licorice contains at least 470 constituents including triterpenes, saponins, flavonoids, isoflavonoids, chalcones, polysaccharides, sugars, and amino acids [6]. Glycyrrhizin (GC; Figure 1) is a major bioactive triterpene glycoside in licorice and elicits anti-inflammatory, anti-ulcer, anti-tumor, anti-allergy, and hepatoprotective effects $[4,5,7]$. In contrast, various licorice constituents, such as flavonoid glycosides, and their aglycones induce apoptosis and act as anti-oxidative, anti-microbial, superoxide scavenging, and antitumor agents $[4,5]$. However, due to technical difficulties in preparing the GC-free licorice extract (LE), the potential function of GC in LE and the interaction between GC and other components of LE are not well understood.

Our laboratory has established several monoclonal antibodies (MAb) against naturally occurring bioactive compounds [6-11]. In our previous work, we prepared an anti-GC MAb for competitive enzymelinked immunosorbent assay (ELISA) and Eastern blotting to identify and quantify GC [12]. Also we reported one-step purification of antigen molecule by immunoaffinity column conjugated with MAb. In these

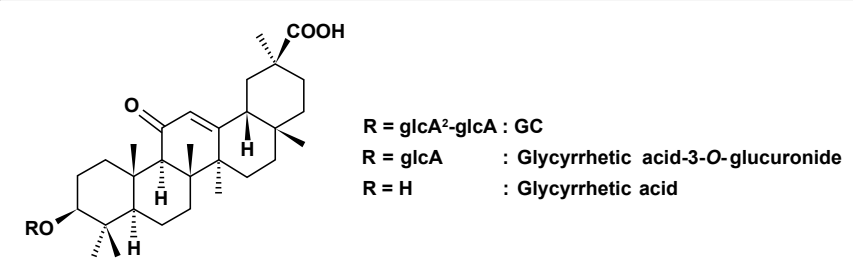

Figure 1: Chemical structures of GC, glycyrrhetic acid-3-O-glucuronide, and glycyrrhetic acid. previous studies, we selected high specific MAb against forskolin [13] and ginsenoside $\mathrm{Rb}_{1}$ [14] for the separation of their antigens, and wide cross-reactive MAb against solasodine glycosides for the separation of all solasodine glycosides [15]. Furthermore, we reported a one-step GC isolation procedure using immunoaffinity columns conjugated with anti-GC MAb to prepare GC-knockout (KO) extract [16,17]. Recently, several groups also reported the preparation of $\mathrm{KO}$ extracts using different approaches such as preparative HPLC and TLC [18-20]. In this study, we investigated the potential role of GC in LE-induced apoptosis using GC-KO extract. GC-KO extract is useful tool to understand the synergistic interaction between GC and other compounds contained in LE. KO extracts provide a novel approach in pharmacological investigations that clarify the functions of bioactive compounds and the interactions between target compounds and other constituents of medicinal and functional food plant extracts.

\section{Materials and Methods}

\section{Chemicals}

Licorice root powder was purchased from Uchida Wakanyaku Corporation (Tokyo, Japan), and LE was prepared according to our previously published procedure [14]. Antibodies against poly (ADPribose) polymerase (PARP), caspase- 3 , and $\beta$-actin were purchased from Cell Signaling Technology (Beverly, MA, USA). Fetal bovine serum (FBS) was purchased from GIBCO (Gaithersburg, MD, USA). All other chemicals were purchased from Wako Pure Chemical Industries (Osaka, Japan).

*Corresponding author: Yukihiro Shoyama, Department of Pharmacognosy, Faculty of Pharmaceutical Sciences, Nagasaki International University, 2825-7 Huis Ten Bosch, Sasebo, Nagasaki 859-3298, Japan, Tel: +81956205622; Fax: +8156205740; E-mail: shoyama@niu.ac.jp

Received March 18, 2013; Accepted April 05, 2013; Published April 08, 2013

Citation: Uto T, Tung NH, Morinaga O, Shoyama Y (2013) Interaction Analysis of Glycyrrhizin on Licorice Extract-Induced Apoptosis of Human Leukemia Cells by Knockout Extract. Nat Prod Chem Res 1: 105. doi:10.4172/2329-6836.1000105

Copyright: (c) 2013 Uto T, et al. This is an open-access article distributed under the terms of the Creative Commons Attribution License, which permits unrestricted use, distribution, and reproduction in any medium, provided the original author and source are credited. 
Citation: Uto T, Tung NH, Morinaga O, Shoyama Y (2013) Interaction Analysis of Glycyrrhizin on Licorice Extract-Induced Apoptosis of Human Leukemia Cells by Knockout Extract. Nat Prod Chem Res 1: 105. doi:10.4172/2329-6836.1000105

\section{Preparation of GC-KO extract using immunoaffinity columns conjugated with anti-GC Mab}

Anti-GC MAb immunoaffinity columns and GC-KO extracts were prepared as described previously [16,17]. In brief, purified antiGC MAb in coupling buffer (Bio-Rad Affi-gel $\mathrm{Hz}$ coupling buffer) was dialyzed and oxidized with $\mathrm{NaIO}_{4}$. Glycerol was then added to the reaction mixture and dialyzed. Affi-Gel $\mathrm{Hz}$ gel (Bio-Rad) was added to the above reaction mixture, and the resulting hydrazone gel was packed into a plastic column. Twelve milligrams of LE in loading buffer $(5 \% \mathrm{MeOH})$ was applied to the column, and the loading buffer was continuously circulated overnight at $4^{\circ} \mathrm{C}$ to enhance binding efficiency. After washing the column with loading buffer, the binding fraction was eluted with elution buffer $(20 \mathrm{mM}$ phosphate buffer containing $30 \% \mathrm{MeOH})$. Finally, each fraction was deionized and the solvent was lyophilized. The concentrations of GC in LE and GC-KO fractions were determined using ELISA. Fractions were then subjected to thin layer chromatography (TLC) with $\mathrm{n}-\mathrm{BuOH}: \mathrm{H}_{2} \mathrm{O}: \mathrm{CH}_{3} \mathrm{COOH}(7: 2: 1)$ as the developing solvent, and stained with $\mathrm{H}_{2} \mathrm{SO}_{4}$ or analyzed by Eastern blot analysis.

\section{Eastern blot analysis}

GC, LE, and GC-KO extracts were applied to a polyethersulfone (PES) membrane and developed with acetonitrile: $\mathrm{H}_{2} \mathrm{O}$ :formic acid (45:55:2). The developed PES membrane was dried and immersed in $\mathrm{NaIO}_{4}(10 \mathrm{mg} / \mathrm{ml})$ for $1 \mathrm{~h}$. After washing with water, $50 \mathrm{mM}$ carbonate buffer solution ( $\mathrm{pH}$ 9.6) containing 1\% BSA was added and stirred for another $3 \mathrm{~h}$. The PES membrane was washed and stained using standard protocols of Eastern blot analysis with anti-GC MAb [12,21].

\section{HPLC fingerprints of LE and GC-KO extract}

The standard compounds, i.e., GC, liquiritin, liquiritigenin and isoliquiritigenin, were dissolved in $\mathrm{MeOH}$ as $2.0 \mathrm{mg} / \mathrm{ml}$ stock solutions and stored at $4^{\circ} \mathrm{C}$ until use. The mixture of standard compounds was prepared by mixing equal volumes of stock solutions. A lyophilized $\mathrm{LE}$ and GC-KO extract were dissolved in $\mathrm{MeOH}$ as $30 \mathrm{mg} / \mathrm{ml}$ stock solution. HPLC analysis was performed using a TOSOH 8020 (Tokyo, Japan) equipped with a TSKgel ODS-100V $(5 \mu \mathrm{m}, 250 \times 4.6 \mathrm{~mm})$ and an UV-8020 detector (Tosoh, Tokyo, Japan). $20 \mu \mathrm{l}$ of the mixture of standard compounds or $10 \mu \mathrm{l}$ of GC-KO extract were injected into the column and eluted at room temperature with a constant flow rate of 1.0 $\mathrm{ml} / \mathrm{min}$. Acetonitrile (solvent $\mathrm{A}$ ) and $0.15 \%$ acetic acid- $\mathrm{H}_{2} \mathrm{O}$ (solution $\mathrm{B})$ were used in the mobile phase. Analysis was performed as follows: 0-20 min, hold 20\% A; 20-60 min, liner gradient from 20\% A to $100 \%$ A; $60-70$ min, liner gradient from $100 \%$ A to $20 \%$ A. The detection wavelength was set to $254 \mathrm{~nm}$.

\section{Cell culture and treatment}

Human leukemia HL-60 cell line and murine macrophage RAW264 were obtained from RIKEN Bio Resource Center Cell Bank, and cultured at $37^{\circ} \mathrm{C}$ under $5 \% \mathrm{CO}_{2}$ in RPMI 1640 medium or Dulbecco's modified Eagle's medium (DMEM) containing 10\% FBS, respectively. LE, GC, and GC-KO extracts were dissolved in dimethyl sulfoxide (DMSO) and diluted in medium at the final concentration of $0.2 \%$ DMSO $(\mathrm{v} / \mathrm{v})$. Control cells were treated with the same concentration of $\operatorname{DMSO}(0.2 \%, \mathrm{v} / \mathrm{v})$.

\section{Cell viability}

Cell viability was determined by the 3-(4,5-dimethylthiazol-2-yl)2,5-diphenyltetrazolium bromide (MTT) assay, as described previously $[22,23]$. HL-60 cells $\left(1 \times 10^{4}\right.$ cells/well $)$ in 96 -well plates were treated with
LE, GC, or GC-KO extract for $24 \mathrm{~h}$ or $48 \mathrm{~h}$. At the end of treatment, MTT solutions were added to each well, and the cells were incubated for another $4 \mathrm{~h}$. The precipitated MTT-formazan was dissolved with $0.04 \mathrm{~N} \mathrm{HCl}$-isopropanol, and formazan absorbance was measured at $595 \mathrm{~nm}$ using a microplate reader (Immuno Mini NJ-2300, Nihon InterMed, Tokyo, Japan).

\section{Nuclear morphology assay}

HL-60 cells $\left(1 \times 10^{6}\right.$ cells $)$ were plated in 6 -cm dish, and then treated with LE for $48 \mathrm{~h}$. At the end of treatment, cells were harvested, washed with PBS, and fixed with $1 \%$ glutaraldehyde for $30 \mathrm{~min}$. After washing with PBS, cells were stained with Hoechst 33258 for 10 min and washed again with PBS. Nuclear morphology was then observed using a fluorescence microscope (Eclipse E600, Nikon, Tokyo, Japan).

\section{DNA fragmentation analysis}

DNA fragmentation was examined using a previously described method [22,23]. HL-60 cells $\left(1 \times 10^{6}\right.$ cells) were treated with LE for various periods. Treated cells were harvested and resuspended in lysis buffer (50 mM Tris- $\mathrm{HCl}, \mathrm{pH} 8.0,10 \mathrm{mM}$ EDTA, and 0.5\% SDS) with $0.2 \mathrm{mg} / \mathrm{ml} \mathrm{RNase} \mathrm{A}$ and incubated at $56^{\circ} \mathrm{C}$ for $30 \mathrm{~min}$. Proteinase $\mathrm{K}$ was then added and incubated for another $3 \mathrm{~h}$. DNA was separated on a $2 \%$ agarose gel and visualized under UV illumination after staining with ethidium bromide.

\section{Western blot analysis}

HL-60 cells were plated in $3 \times 6 \mathrm{~cm}$ dishes $\left(1 \times 10^{6}\right.$ cells $/$ dish $)$, and then treated with LE, GC-KO extract, or GC for various periods. Harvested cells were lysed, and the supernatants were boiled for $5 \mathrm{~min}$. Protein concentration was determined using a dye-binding protein assay kit (Bio-Rad) according to the manufacturer's instructions. Equal quantities of protein were subjected to SDS-PAGE and electrophoretically transferred to PVDF membranes. After blotting, the membrane was incubated with specific primary antibody overnight at $4^{\circ} \mathrm{C}$, and further incubated for $1 \mathrm{~h}$ with HRP-conjugated secondary antibody. Bound antibodies were detected using the ECL plus Western Blotting Detection System with a LAS4000mini (GE Healthcare). $\beta$-Actin was used as the internal control of whole cell lysate.
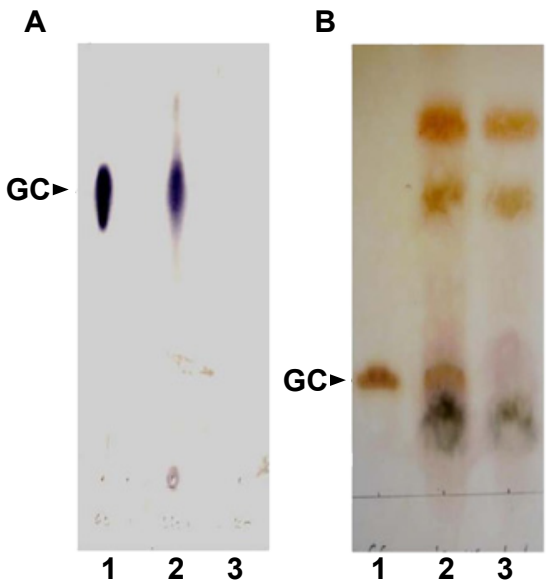

Figure 2: Eastern blotting using anti-GC MAb (A) and TLC profiles (B). Lanes 1,2 , and 3 indicate $G C$ standard, LE, and GC-KO extract, respectively. After the development of TLC plate, the spots were observed by Eastern blot analysis or staining with $\mathrm{H}_{2} \mathrm{SO}_{4}$. Eastern blotting and TLC were repeated thrice and similar results were obtained. 


\section{Analysis of cellular GC accumulation}

HL-60 cells $\left(1 \times 10^{6}\right.$ cells $)$ were plated in 6 - $\mathrm{cm}$ dish, and then treated with GC for various periods. After incubation, cells were washed twice with PBS and resuspended in $200 \mu \mathrm{l}$ of PBS. Cells were sonicated and protein concentration was determined using a dye-binding protein assay kit (Bio-Rad). GC in cell protein was measured using competitive ELISA with anti-GC MAb, as described previously $[12,17]$.

\section{Immunocytochemistry}

RAW264 cells $\left(1 \times 10^{5}\right.$ cells) in chamber slide were treated with GC for $6 \mathrm{~h}$. The treated cells were fixed for $10 \mathrm{~min}$ in $4 \%$ paraformaldehyde in PBS on ice. After wash with PBS, the cells were treated with $0.2 \%$ Triton X-100 for 2 min for membrane permeabilization. Then the cells were blocked with $1 \%$ BSA for $1 \mathrm{~h}$ and incubated with anti-GC MAb overnight at $4^{\circ} \mathrm{C}$. The cells were rinsed and then incubated with FITClabeled anti-mouse IgG for $1 \mathrm{~h}$. Images of cellular immunofluorescence were examined under a confocal laser scanning microscope, LSM5Pascal (Carl Zeiss).

\section{Statistical analyses}

All data were derived from at least three independent experiments. Differences between groups were tested using Student's $t$-test and $\mathrm{P}$ values less than 0.01 were considered significant.

\section{Results and Discussion}

\section{Preparation and characterization of the GC-KO extract}

In our previous study, we demonstrated the preparation of anti-GC MAb [12]. Figure 1 shows the chemical structure of GC, glycyrrhetic acid-3-O-glucuronide, and glycyrrhetic acid. Cross reactivity of the
anti-GC MAb with glycyrrhetic acid-3-O-glucuronide and glycyrrhetic acid was $0.585 \%$ and $1.865 \%$, respectively. Cross reactivity with other related compounds (deoxycholic acid, ursolic acid, and oleanolic acid) was less than $0.005 \%$. Using the GC-specific MAb, we prepared antiGC immunoaffinity columns for the preparation of the GC-KO extract [17]. Twelve milligrams of LE, which contains $1275 \mu \mathrm{g}$ of GC, was dissolved in loading buffer and applied to the anti-GC immunoaffinity column. After circulation of the loading buffer to enhance the binding efficiency of GC, the unbound fraction was collected. Subsequently, the column was washed completely, and the bound fraction was removed using the elution buffer. After deionization and lyophilization of each fraction, the concentration of GC was determined by ELISA using antiGC MAb. The unbound fraction contained $3.50 \mu \mathrm{g}$ of GC $(0.27 \%$ of the loaded GC), whereas the bound fraction contained $1269.26 \mu \mathrm{g}$ of GC (99.55\% of the loaded GC), suggesting that the anti-GC immunoaffinity column functioned and then eliminated $99.55 \%$ of GC from LE.

In order to confirm this evidence, we next performed Eastern blot analysis, the high-sensitivity on-membrane quantitative staining using anti-GC MAb [12,21]. Figure 2A clearly showed the absence of GC in the unbound fraction (lane 3). Furthermore, TLC analysis demonstrated high concentration of GC exists together with the other components in LE (lane 2; Figure 2B). However, the spot of GC in unbound fraction specifically disappeared (lane 3; Figure 2B).

In order to make clear the more detail characterization of GCKO extract, we analyzed the HPLC fingerprint of LE and GC-KO extract because we have indicated that the HPLC fingerprint of the leaf extract of Eriobotrya japonica, which strongly suppressed the production of prostaglandin $\mathrm{E}_{2}$ and nitric oxide in lipopolysaccharidetreated macrophages [24], showed the typical profile of the triterpene

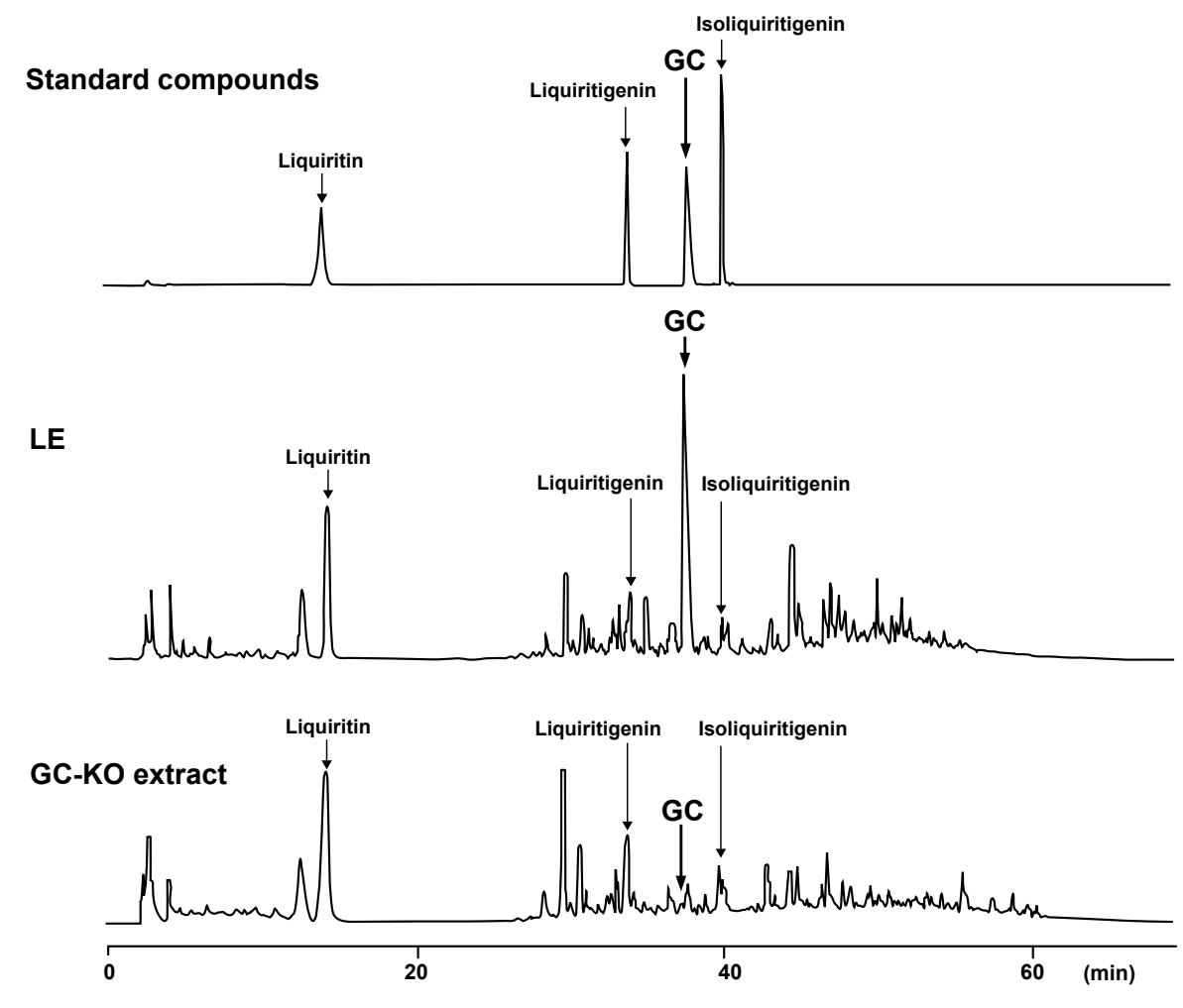

Figure 3: HPLC profile of GC and three licorice flavonoids in LE and GC-KO extract. 
Citation: Uto T, Tung NH, Morinaga O, Shoyama Y (2013) Interaction Analysis of Glycyrrhizin on Licorice Extract-Induced Apoptosis of Human Leukemia Cells by Knockout Extract. Nat Prod Chem Res 1: 105. doi:10.4172/2329-6836.1000105

Page 4 of 6

constituents, and four major triterpenes including corosolic acid, ursolic acid, maslinic acid and oleanolic acid were highlighted relatively [25]. As shown in Figure 3, GC-KO extract contained three licorice flavonoids, such as liquiritin, liquiritigenin, and isoliquiritigenin, in the same pattern as LE. However, the peak corresponding to GC was undetectable in GC-KO extract.

Taken together, these results clearly indicate the effective elimination of GC from LE by the anti-GC immunoaffinity column, and suggest that the unbound fraction was the GC-KO extract.

\section{LE-Induced apoptosis of HL-60 cells}

We examined the effects of LE on cell viability of HL-60 cells using the MTT assay. Cells were treated with $25-200 \mu \mathrm{g} / \mathrm{mL} \mathrm{LE}$ for $24 \mathrm{~h}$ and $48 \mathrm{~h}$. As shown in figure 4A, LE significantly inhibited cell proliferation in a dose and time-dependent manner with $\mathrm{IC}_{50}$ values of $189.7 \mu \mathrm{g} /$ $\mathrm{mL}$ and $130.2 \mu \mathrm{g} / \mathrm{mL}$ after $24 \mathrm{~h}$ and $48 \mathrm{~h}$, respectively. To determine whether LE-induced cell death is mediated by apoptosis, nuclear morphological features of apoptotic cells were examined. Staining of the cells with Hoechst 33258 showed that treatment with $200 \mu \mathrm{g} / \mathrm{mL} \mathrm{LE}$ for $48 \mathrm{~h}$ resulted in chromatin condensation (Figure 4B). For further confirmation, DNA fragmentation was investigated (Figure 4C). Moreover, Western blot analysis demonstrated that LE induced PARP cleavage and activated caspase-3; out of which both are hallmarks of apoptosis (Figure 4D). Taken together, these findings indicate that $\mathrm{LE}$ induced apoptosis in HL-60 cells.

\section{Treatment with GC alone fails to suppress cell proliferation}

At $200 \mu \mathrm{g} / \mathrm{mL}$, cell proliferation was strongly suppressed by LE,
A

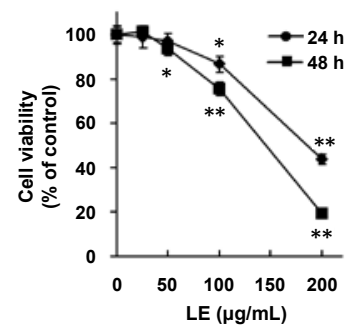

C

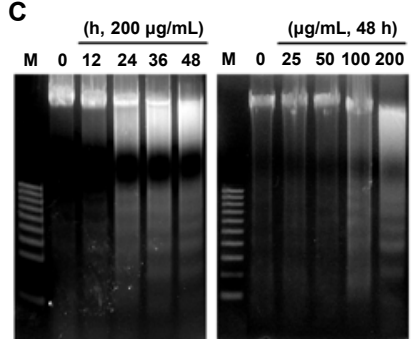

B
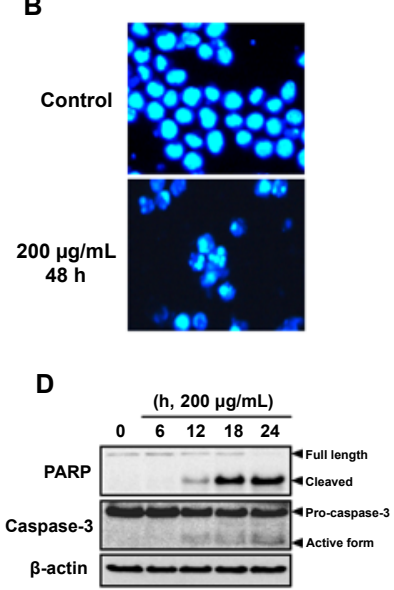

Figure 4: LE induced apoptotic cell death in HL-60. (A) Effects of LE on cell viability. HL-60 cells were treated with the indicated concentrations of LE for $24 \mathrm{~h}$ and $48 \mathrm{~h}$, and cell viability was determined by the MTT assay. Each bar indicates the mean \pm S.D. of three individual experiments. $P<0.01$ and $P<0.001$ indicate significant differences from control. (B) Effects of LE on nuclear morphology. $\mathrm{HL}-60$ cells were treated with $200 \mu \mathrm{g} / \mathrm{mL}$ LE for $48 \mathrm{~h}$. To examine nuclear morphology, the cells ware fixed, stained with Hoechst 33258, and visualized using a fluorescent microscope. (C) Induction of DNA fragmentation by LE. HL-60 cells were treated with LE at the indicated concentrations and times, and DNA was extracted and separated on $2 \%$ agarose gel. (D) Effects of LE on PARP and caspase-3. HL-60 cells were treated with $200 \mu \mathrm{g} / \mathrm{mL}$ LE for the indicated times. Cells were lysed, and PARP, caspase-3, and $\beta$-actin protein levels were determined using Western blot analysis. Experiments were repeated thrice and similar results were obtained. and typical apoptotic features were observed. ELISA using the antiGC MAb indicated that $200 \mu \mathrm{g}$ LE contained $21.2 \pm 1.24 \mu \mathrm{g}$ of GC. In order to determine whether GC alone can induce cell death, we treated cells with GC at $2.5-40 \mu \mathrm{g} / \mathrm{mL}$ for $48 \mathrm{~h}$. As shown in figure $5 \mathrm{~A}$ GC had no significant effect on cell viability, suggesting that at these concentrations GC alone does not directly induce cell death. Next, we investigated whether or not GC uptakes into cells to exert unknown potential function. Cells were treated cells with $21.2 \mu \mathrm{g} / \mathrm{ml} \mathrm{GC}$ for 1-12 $\mathrm{h}$, and then GC concentrations in cell lysates were determined. ELISA experiments using the anti-GC MAb indicated that GC was indeed taken up by the cells (Figure 5B). Furthermore, in order to confirm the uptake of GC in the different cell line, we examined it using a murine macrophage RAW264 cells stimulated with lipopolysaccharide (LPS), which is inflammation model, resulted that clear incorporation of GC into cells was observed as shown in (Figure 6). These results indicated that, although GC alone cannot induce the cell death, GC can accumulate in cells.

\section{GC synergistically induced cell death with the other constituents of $\mathrm{LE}$}

To further explore the role of GC in LE-induced apoptosis, we treated cells with LE $(200 \mu \mathrm{g} / \mathrm{mL}), \mathrm{GC}$ alone $(21.2 \mu \mathrm{g} / \mathrm{mL}), \mathrm{GC}-\mathrm{KO}$ extract $(178.8 \mu \mathrm{g} / \mathrm{mL})$, or the combination of GC $(21.2 \mu \mathrm{g} / \mathrm{mL})$ and GC$\mathrm{KO}$ extract $(178.8 \mu \mathrm{g} / \mathrm{mL})$. Treatment with LE inhibited cell viability (inhibition ratio $(\mathrm{IR})=83.0 \%$ ) (Figure $7 \mathrm{~A}$ ). Because GC alone did not significantly suppress cell viability, it was expected that the GC$\mathrm{KO}$ extract would suppress cell proliferation to the same degree as LE. However, the inhibitory effect of GC-KO extract was attenuated compared with $\mathrm{LE}(\mathrm{IR}=24.8 \%)$, and the combination of GC-KO extract and GC significantly rescued this inhibitory effect $(I R=43.5 \%)$. Similarly, Western blotting experiments demonstrated that caspase- 3 activation by the GC-KO extract was weaker than that of LE, and addition of GC
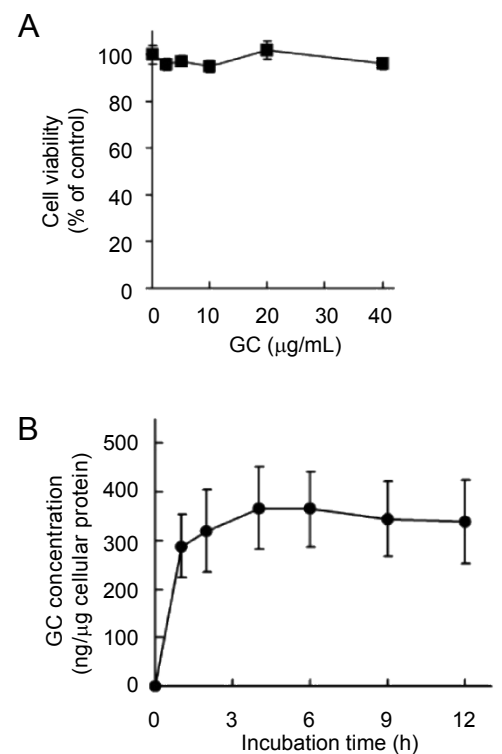

Figure 5: (A) Effects of $\mathrm{GC}$ on cell viability. HL-60 cells were treated with the indicated concentrations of GC for $48 \mathrm{~h}$, and cell viability was determined by the MTT assays. Data are presented as the mean \pm S.D. of three independent experiments. There were no significant differences between control and treated cells $(P>0.01)$. (B) Uptake of GC into cells. HL-60 cells were treated with 21.2 $\mu \mathrm{g} / \mathrm{mL} \mathrm{GC}$ for the indicated times. The cells were sonicated and cellular $\mathrm{GC}$ was determined by ELISA using an anti-GC MAb. Experiments were repeated thrice and similar results were obtained. 
Citation: Uto T, Tung NH, Morinaga O, Shoyama Y (2013) Interaction Analysis of Glycyrrhizin on Licorice Extract-Induced Apoptosis of Human Leukemia Cells by Knockout Extract. Nat Prod Chem Res 1: 105. doi:10.4172/2329-6836.1000105

Page 5 of 6

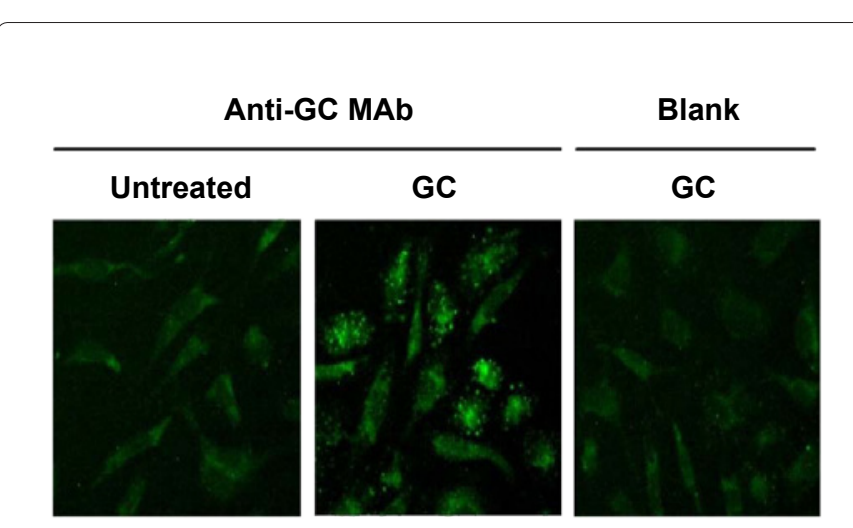

Figure 6: Uptake of GC into murine macrophage RAW264 cells. The LPSstimulated RAW264 cells were treated with $10.6 \mu \mathrm{g} / \mathrm{mL} \mathrm{GC}$ for $6 \mathrm{~h}$. The cells were fixed, reacted with anti-GC MAb followed by FITC-conjugated secondary antibody, and then detected by a confocal laser scanning microscope. Experiments were repeated three times and similar results were obtained.

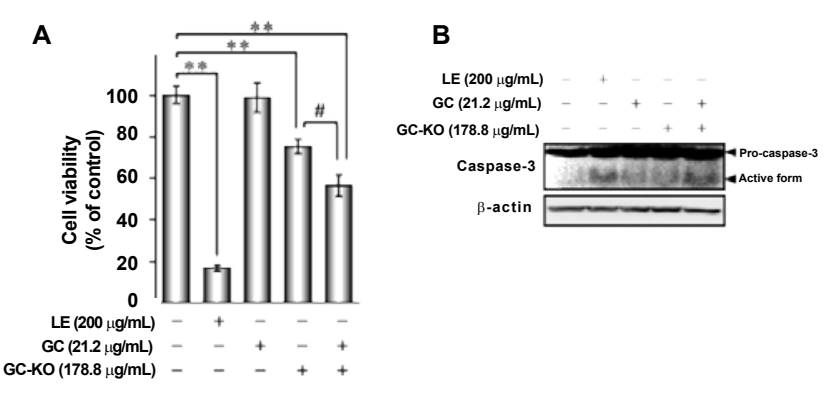

Figure 7: The effects of the GC-KO extract and the combination of GC-KO extract and GC on cell viability (A) and caspase- 3 activation (B). (A) HL-60 cells were treated with LE, GC, GC-KO extract, or the combination of GC and GC-KO extract for $48 \mathrm{~h}$, and cell viability was determined by the MTT assay. Data are presented as the mean \pm S.D. of three individual experiments. $P<0.001$ indicates significant differences from control. ${ }^{\#} P<0.001$ indicates significant differences between the GC-KO extract and the combination of GC and GC-KO extract. (B) $\mathrm{HL}-60$ cells were treated with LE, GC, GC-KO extract, and the combination of GC and GC-KO extract for $24 \mathrm{~h}$. Cells were lysed and caspase- 3 and $\beta$-actin protein levels were determined using Western blot analysis. Experiments were repeated thrice and similar results were obtained.

to the GC-KO extract rescued the induction of caspase-3 (Figure 7B). These data indicate that GC alone cannot induce apoptotic cell death but may induce apoptosis in synergy with the other constituents of LE.

\section{Conclusions}

In conclusion, we revealed a potential function of GC in LE using the GC-KO extract that contains all constituents of LE except GC. LE strongly induced apoptotic cell death in HL-60 cells. Although GC alone could not directly induce apoptosis, the co-treatment with GC and GC$\mathrm{KO}$ extract coordinately accelerated apoptosis. These data suggest that GC can contribute to the apoptotic effects of LE in combination with the other LE constituents. We had previously prepared various MAb against natural bioactive compounds including terpenoids, alkaloids, saponins, and phenolics $[8-11,26,27]$. Subsequently, one-step purification of target compounds from crude mixtures was successfully achieved using immunoaffinity columns conjugated with anti-ginsenoside $\mathrm{Rb} \mathrm{B}_{1} \mathrm{MAb}$ [14], anti-forskolin MAb [13], anti-solasodine glycosides MAb [15], and anti-GC MAb [28]. Therefore, individual KO extracts can be easily prepared using immunoaffinity columns conjugated with these MAbs.
This newly developed system may open the wide applications in the field of natural medicines like that an inhibitor and/or an activator in crude medicine can be found out easily using $\mathrm{KO}$ extracts.

The health benefits of medicinal and functional food plants have recently attracted increasing interest. However, the plant extracts are complex mixtures of active phytochemicals, which act synergistically or additively on specific and/or multiple molecular and cellular targets. Therefore, KO extracts are critical tools for determining the potential functions of target constituents from crude plant extracts using in vitro and in vivo assays.

\section{Acknowledgements}

This work was funded by the Asahi Beer Science Promoting Foundation and Sasakawa Scientific Research Grant from Japan Science Society. The research in this paper was also supported in part by the Japan Food Chemical Research Foundation. The authors would like to thank Enago (www.enago.jp) for the English language review.

\section{References}

1. Pharmacopeia of the People's Republic of China, Pharmacopoeia Commission of People's Republic of China, 2010

2. (2011) Japanese Pharmacopoeia, (16thedn), The Society of Japanese Pharmacopoeia.

3. Aly AM, Al-Alousi L, Salem HA (2005) Licorice: a possible anti-inflammatory and anti-ulcer drug. AAPS PharmSciTech 6: E74-82.

4. Asl MN, Hosseinzadeh H (2008) Review of pharmacological effects of Glycyrrhiza sp. and its bioactive compounds. Phytother Res 22: 709-724.

5. Wang ZY, Nixon DW (2001) Licorice and cancer. Nutr Cancer 39: 1-11.

6. Zhang Q, Ye M (2009) Chemical analysis of the Chinese herbal medicine GanCao (licorice). J Chromatogr A 1216: 1954-1969.

7. Kuttan G, Pratheeshkumar P, Manu KA, Kuttan R (2011) Inhibition of tumour progression by naturally occurring terpenoids. Pharm Biol 49: 995-1007.

8. Xuan L, Tanaka H, Xu Y, Shoyama Y (1999) Preparation of monoclonal antibody against crocin and its characterization. Cytotechnology 29: 65-70.

9. Tanaka H, Fukuda N, Shoyama Y (1999) Formation of monoclonal antibody against a major ginseng component, ginsenoside $\mathrm{Rb}_{1}$ and its characterization. Cytotechnology 29: 115-120.

10. Fukuda N, Tanaka H, Shoyama Y (2000) Formation of monoclonal antibody against a major ginseng component, ginsenoside $\mathrm{Rg}_{1}$ and its characterization. Monoclonal antibody for a ginseng saponin. Cytotechnology 34: 197-204.

11. Ishiyama M, Shoyama Y, Murakami H, Shinohara H (1996) Production of monoclonal antibodies and development of an ELISA for solamargine. Cytotechnology 18: 153-158.

12. Shan S, Tanaka H, Shoyama Y (2001) Enzyme-linked immunosorbent assay for glycyrrhizin using anti-glycyrrhizin monoclonal antibody and an eastern blotting technique for glucuronides of glycyrrhetic acid. Anal Chem 73: 5784-5790.

13. Yanagihara H, Sakata R, Minami H, Tanaka H, Shoyama Y, et al. (1996) Immunoaffinity column chromatography against forskolin using an anti-forskolin monoclonal antibody and its application. Analytica Chimica Acta 335: 63-70.

14. Fukuda N, Tanaka H, Shoyama Y (2000) Applications of ELISA, western blotting and immunoaffinity concentration for survey of ginsenosides in crude drugs of Panax species and traditional Chinese herbal medicines. Analyst 125: 1425-1429.

15. Putalun W, Tanaka H, Shoyama Y (1999) Rapid separation of solasodine glycosides by an immunoaffinity column using anti-solamargine monoclonal antibody. Cytotechnology 31: 153-158.

16. Xu J, Tanaka H, Shoyama Y (2007) One-step immunochromatographic separation and ELISA quantification of glycyrrhizin from traditional Chinese medicines. J Chromatogr B Analyt Technol Biomed Life Sci 850: 53-58.

17. Uto T, Morinaga O, Tanaka H, Shoyama Y (2012)Analysis of the synergistic effect of glycyrrhizin and other constituents in licorice extract on lipopolysaccharide- 
Citation: Uto T, Tung NH, Morinaga O, Shoyama Y (2013) Interaction Analysis of Glycyrrhizin on Licorice Extract-Induced Apoptosis of Human Leukemia Cells by Knockout Extract. Nat Prod Chem Res 1: 105. doi:10.4172/2329-6836.1000105

induced nitric oxide production using knock-out extract. Biochem Biophys Res Commun 417: 473-478.

18. Liu Y, Zhou JL, Liu P, Sun S, Li P (2010) Chemical markers' fishing and knockout for holistic activity and interaction evaluation of the components in herbal medicines. J Chromatogr A 1217: 5239-5245.

19. Zhu M, Tang Y, Duan JA, Guo J, Guo S, et al. (2010) Roles of paeoniflorin and senkyunolide I in SiWu decoction on antiplatelet and anticoagulation activities. J Sep Sci 33: 3335-3340.

20. Kong WJ, Wang JB, Zang QC, Jin C, Wang ZW, et al. (2011) A nove "target constituent knock-out" strategy coupled with TLC, UPLC-ELSD and microcalorimetry for preliminary screening of antibacterial constituents in Calculus bovis. J Chromatogr B Analyt Technol Biomed Life Sci 879: 35653573.

21. Morinaga O, Fujino A, Tanaka H, Shoyama Y (2005) An on-membrane quantitative analysis system for glycyrrhizin in licorice roots and traditional Chinese medicines. Anal Bioanal Chem 383: 668-672.

22. Hou DX, Uto T, Tong X, Takeshita T, Tanigawa S, et al. (2004) Involvement of reactive oxygen species-independent mitochondrial pathway in gossypolinduced apoptosis. Arch Biochem Biophys 428: 179-187.

23. Tung NH, Uto T, Sakamoto A, Hayashida Y, Hidaka Y, et al. (2013)
Antiproliferative and apoptotic effects of compounds from the flower of Mammea siamensis (Miq.) T Anders on human cancer cell lines. Bioorg Med Chem Lett 23: 158-162.

24. Uto T, Suangkaew N, Morinaga O, Kariyazono H, Oiso S, et al. (2010) Eriobotryae folium extract suppresses LPS-induced iNOS and COX2 expression by inhibition of NF-kappaB and MAPK activation in murine macrophages. Am J Chin Med 38: 985-994.

25. Uto T, Sakamoto A, Tung NH, Fujiki T, Kishihara K, et al. (2013) Anti-proliferative activities and apoptosis induction by triterpenes derived from Eriobotrya japonica in human leukemia cell lines. Int J Mol Sci 18: 4106-4120.

26. Kim JS, Tanaka H, Shoyama Y (2004) Immunoquantitative analysis for berberine and its related compounds using monoclonal antibodies in herbal medicines. Analyst 129: 87-91.

27. Lu Z, Morinaga O, Tanaka H, Shoyama Y (2003) A quantitative ELISA using monoclonal antibody to survey paeoniflorin and albiflorin in crude drugs and traditional Chinese herbal medicines. Biol Pharm Bull 26: 862-866.

28. Zhu S, Shimokawa S, Tanaka H, Shoyama Y (2004) Development of an assay system for saikosaponin a using anti-saikosaponin a monoclonal antibodies. Biol Pharm Bull 27: 66-71. 